\title{
REGULACIÓN Y CONTROL DE LA PUBLICIDAD DE LAS OFERTAS PÚBLICAS DE VALORES MOBILIARIOS: ¿EXISTE EN NUESTRO ACTUAL ORDENAMIENTO UN CONFLICTO DE COMPETENCIA ENTRE CONASEV E INDECOPI SOBRE LA MATERIA?
}

\section{Eduardo Campodónico Figueroa ${ }^{1}$}

Abogado por la Universidad de Lima. Profesor del curso Derecho del Mercado de Valores en la Universidad de Lima y en la Universidad Peruana de Ciencias Aplicadas (UPC).

\section{INTRODUCCIÓN}

U

na de las razones esenciales por las que se regulan las operaciones que se realizan en el mercado de valores es el carácter de "públicas" que tienen la gran mayoría de ellas. Al menos en nuestro ordenamiento, el artículo 1 de la Ley del Mercado de Valores -en adelante, LMV- señala de manera expresa que

... quedan comprendidas en la presente ley las ofertas públicas de valores mobiliarios y sus emisores, los valores de oferta pública... Salvo mención expresa en contrario, sus disposiciones llas de la LMV] no alcanzan a las ofertas privadas de valores.

Debe aclararse que el presente artículo refleja las opiniones estrictamente personales de su autor y no compromete en nada a la Comisión Nacional Supervisora de Empresas y Valores (Conasev), institución donde labora y desempeña el cargo de analista de la Gerencia de Asesoria Jurídica. 
No es muy difícil intuir cuándo una oferta de valores mobiliarios ${ }^{2}$ es pública, al menos coloquialmente hablando. Así, si hiciésemos una encuesta podríamos encontrar las siguientes respuestas a la pregunta: "A su criterio, ¿cuándo una oferta de valores mobiliarios $\multimap$ una oferta en generales pública?": i) cuando va dirigida al público, ii) cuando se divulga entre muchas personas por cualquier medio, o iii) cuando se utiliza un medio masivo de comunicación (periódicos, revistas, radio, televisión, internet, entre otros). Sin embargo, para fines regulatorios, como es sencillo advertir, no es eficiente que sean las definiciones intuitivas las que determinen cuándo una oferta de valores mobiliarios es pública o no.

En este orden de ideas, el artículo 4 de la LMV prescribe que es oferta pública de valores mobiliarios

... la invitación, adecuadamente difundida, que una o más personas naturales o jurídicas dirigen al público en general, o a determinados segmentos de éste, para realizar cualquier acto jurídico referido a la colocación, adquisición o disposición de valores mobiliarios.

El Reglamento de Oferta Pública Primaria y Venta de Valores Mobiliarios, aprobado por resolución Conasev 141-98-EF/ 94.10, contiene regulación adicional de carácter reglamentario que ayuda a determinar con mayor precisión el alcance de la definición de la LMV antes transcrita ${ }^{3}$. Co-

2 En adelante, cuando hagamos mención a "ofertas de valores mobiliarios" u "ofertas públicas de valores mobiliarios" nos estaremos refiriendo, indistintamente, a ofertas para comprar o vender valores.

3 Ver el artículo 6 del Reglamento de Oferta Pública Primaria que desarrolla los términos clave de la definición contenida en la LMV: i) invitación; ii) adecuadamente difundida; iii) público en general; iv) segmento del público; v) acto de inversión. mo se aprecia, al menos legislativamente, se han puntualizado los componentes del término bajo análisis, lo que, desde nuestra perspectiva, facilita al organismo supervisor realizar una mejor labor fiscalizadora. En resumen, y para no entrar en mucho detalle aún, podemos señalar que la oferta pública de valores mobiliarios es la que se dirige al público en general o a un segmento de éste, utilizando cualquier medio de difusión o comunicación adecuado que permita hacerla conocida por la mayor cantidad de personas posible para que así el oferente pueda contratar con ellas. Debe aclararse, no obstante, que el medio que se utilice no determina indefectiblemente la calidad de "pública" de una oferta de valores mobiliarios, aspecto este último en el que ahondaremos luego.

Sin embargo, hoy en día, dado los costos de transacción que se ven ampliamente reducidos por su utilización, toda oferta que desee dirigirse a una gran cantidad de personas suele canalizarse a través de los denominados "medios masivos de comunicación" ${ }^{4}$. Avisos televisivos, periodísticos o radiales constituyen actualmente la manera más efectiva de ofertar bienes y servicios al público, sin mencionar el internet, que cobra mayor vigencia cada día. Y el mercado de valores no es ajeno a esta publicidad.

Desde hace ya mucho tiempo, una oferta de valores mobiliarios -máxime en un mercado de valores desarrollado- que pretenda dirigirse al público en general o a un segmento de éste (oferta pública), deberá, necesariamente, canalizarse a través de los medios masivos de comunicación social. No bastan los denominados "road shows" que los bancos de inversión -underwriters- suelen formar para colocar los valo-

4 Televisión, radio, prensa escrita e internet, fundamentalmente. 
res que promueven, justamente porque buena parte de los recursos de la economía se encuentra ampliamente dispersa entre un sinnúmero de personas naturales y/o jurídicas que pueden ser denominadas "comunes" (los road shows son dirigidos básicamente a inversores institucionales ${ }^{5}$ ). Si lo que se desea con una oferta de valores mobiliarios es obtener suficientes recursos para el financiamiento de proyectos empresariales, resulta a veces ventajoso movilizar muchos de ellos hacia tales proyectos (apelación al ahorro público), que si bien individualmente considerados no son lo suficientemente representativos, sumados todos pueden satisfacer en exceso su demanda ${ }^{6}$.

Por lo anterior, es común observar en periódicos y revistas (especializados o no), o avisos televisivos en algunos casos, anuncios sobre ofertas públicas de valores mobiliarios. Se hace necesaria, entonces, la regulación de la publicidad de las ofertas públicas, es decir, de aquellos anuncios que el oferente o su promotor realizan a efectos de informar de la existencia de una oferta; ya que si tales mecanismos son los

5 Ver artículo 8, literal $j$, del TÚO de la LMV, aprobado por decreto supremo 093-2002-EF y publicado en el diario oficial El Peruano el 15 de junio de 2002.

6 Aunque en muchos de los casos los inversores institucionales pueden proveer suficientes recursos para el financiamiento empresarial, por cuestiones de limites operacionales o preferencias de inversión, incluso establecidas en reglamentos internos, es necesario recurrir eventualmente al denominado inversor individual, máxime cuando hablamos de grandes emisiones. Es común que los underwriters en ese tipo de emisiones "dividan" la colocación entre el "sector institucional" y el "sector minorista". De ahi la importancia de la publicidad o difusión eficiente de la oferta, sobre todo para llegar al segundo sector. Por otro lado, cuando se pretenden comprar valores en sociedades con accionariado muy disperso, la publicidad cobra igual significación. que se utilizan comúnmente para apelar al ahorro público, el engaño, error o confusión pueden fácilmente canalizarse o gestarse, dependiendo del caso, a través de dichos medios.

Lo antes expresado, como es obvio, no es privativo del mercado financiero $\mathrm{ni}$ mucho menos. En realidad, la publicidad cobra mayor relevancia con productos (bienes y/o servicios) distintos de los valores mobiliarios, dada la especialísima y "sofisticada" calidad de éstos ${ }^{7}$. Existen cada vez más regulaciones y jurisprudencia sobre la publicidad de bienes y servicios, no siendo nuestro país ajeno a ello. La dación del decreto legislativo 691 -Normas de la Publicidad en Defensa del Consumidor- es un claro ejemplo de esta tendencia en nuestro medio desde hace un buen tiempo. La asimetría de la información existente entre proveedores -para ponernos a "tono" con la regulación peruana sobre la materia- y consumidores genera la intervención del Estado para evitar la

7 Cox, Hillman y Langevoort afirman: "La legislación del mercado de valores existe debido a las necesidades únicas de información que tienen los inversionistas. A diferencia de los automóviles y otros bienes tangibles, los valores mobiliarios no son inherentemente valiosos. Su valor proviene sólo de los derechos que otorgan a su titular sobre los activos y los ingresos del emisor, o del poder de voto que acompan̂a dichos derechos. Por tanto, decidir comprar o vender un valor mobiliario requiere información confiable sobre asuntos como la condición financiera del emisor, sus productos y mercados, su administración y el ambiente regulatorio y la competencia. Con esta información, los inversionistas pueden intentar hacer un estimado razonable del valor presente del paquete de derechos que la propiedad de un valor mobiliario confiere". COX, HILLMAN \& LANGEVOORT. Securities regulation. Cases and materials. Citado por PAYET PUCCIO, José Antonio. "Razones para regular el mercado de valores". Themis. Revista de Derecho 33,1996, p. 96. 
adopción de decisiones que no respondan a un análisis consciente y completo de las ofertas de bienes y/o servicios que los primeros brindan a los segundos. Todo ello en procura de decisiones eficientes (por ejemplo, comprar lo que mejor satisface nuestras necesidades al menor precio posible o recibir el producto que verdaderamente se desea adquirir). El organismo público que tiene por finalidad el cumplimiento de estas prescripciones en el Perú es el Indecopi.

No obstante, mediante el presente artículo intentamos demostrar que la publicidad de las ofertas públicas de valores mobiliarios -que aunque parezca redundante no necesariamente lo es, como veremos seguidamente- es una materia que debe ser regulada y supervisada por el órgano estatal especializado en el mercado de valores, esto es, Conasev. En nuestro concepto, la legislación peruana así lo prescribe aunque de manera no muy clara, pues, como se verá, un análisis superficial nos llevaría a concluir que el Indecopi es el encargado de regular y supervisar toda clase de publicidad, incluso la relativa a las ofertas públicas de valores. Y ello no debe ser así por una simple razón: el mercado de valores cuenta con legislación y regulador independientes, aun cuando en él también se encuentren muy presentes los principios que subyacen a la legislación sobre protección al consumidor (sólo que ésta es de carácter general frente a la del mercado de valores). Esta tendencia mundial de regular y supervisar el mercado de valores por separado de otros mercados de bienes y servicios, merece coherencia en la regulación de la publicidad. En las siguientes líneas pasamos a fundamentar nuestra posición.

\section{PLANTEAMIENTO DEL PROBLEMA: ¿QUÉ DICE LA NORMATIVA?}

De acuerdo con el artículo 11 de la LMV:

La publicidad relativa a la emisión, colocación o intermediación de valores y cualquier otra actividad que se realice en el mercado de valores no debe inducir a confusión o error.

Por su parte, el artículo 12, numeral 3, literal $a$ del anterior Reglamento de Sanciones en el Mercado de Valores, tipificaba como infracción leve "inducir a confusión o error a potenciales inversionistas a través de propaganda relativa a la colocación o intermediación en valores". El vigente Reglamento de Sanciones en el Mercado de Valores -publicado el 23 de octubre de 2001 y aprobado por resolución Conasev 055-2001-EF/94.10-, en el Anexo I, numeral 2.7, establece como infracción grave

inducir a confusión o error mediante publicidad relativa a la emisión, colocación o intermediación de valores y cualquier otra actividad que se realice en el mercado de valores.

Del análisis de las normas transcritas puede advertirse que califican como conducta prohibida en el mercado de valores realizar publicidad sobre ofertas públicas de valores o relativa a cualquier otro acto jurídico propio de dicho mercado, que induzca a error o confusión. Siendo Conasev el órgano regulador y supervisor del mercado de valores, podría inferirse fácilmente que es la institución llamada a regular, intervenir $y$, eventualmente, sancionar cualquier acto de publicidad que se realice en contravención de la disposición de rango legal antes transcrita. Hasta aquí, nues- 
tro artículo no tendría mucho sentido, dada la claridad de la regulación.

No obstante, de acuerdo con el artículo 29 del Texto Único Ordenado del Decreto Legislativo 691 -Normas de Publicidad en Defensa del Consumidor-, aprobado por D.S. 039-2000-ITINCI, a partir de la vigencia de este decreto legislativo:

... todos los organismos integrantes del Estado quedan impedidos de aplicar sanciones en materia de publicidad comercial, debiendo denunciar ante la Comisión de Represión de la Competencia Desleal las infracciones a las normas de publicidad que conozcan en el área de su competencia, a fin de que este órgano proceda a imponer las sanciones que legalmente correspondan. Está prohibido el control previo de la publicidad en cualquier área o sector de la actividad económica, sin excepción. La fiscalización de los anuncios, en todos los casos, sólo podrá realizarse con posterioridad a la difusión de éstos. Es nula cualquier sanción dispuesta por un órgano del Estado que contravenga lo señalado en el presente artículo". [subrayado nuestro].

Es esta norma la que justifica nuestro ensayo. Porque la vigencia de su texto genera la duda razonable de si Conasev es el llamado a reglamentar y hacer cumplir el artículo 11 de la LMV, que, como se vio, por sí solo no ofrece muchas dificultades para su entendimiento. Existen incluso lineamientos divulgados por el Indecopi que señalan expresamente que el cumplimiento del artículo en cuestión de la LMV es de $s u$ exclusiva competencia ${ }^{8}$.

8 Si bien de acuerdo con el artículo 9 del decreto legislativo 807 los lineamientos o pautas que las comisiones $u$ oficinas del Indecopi aprueben no tienen carácter vinculante, teniendo sólo por finalidad orientar a los agentes económicos sobre los alcances y criterios de interpretación de las normas cuya aplicación tiene encomendada cada comisión u oficina, la falta de respuesta clara, expresa y pública de Conasev ante estos
Nosotros consideramos, sin embargo, que la vigencia del artículo transcrito de la Ley de Normas de Publicidad en Defensa del Consumidor no impide a Conasev intervenir, regular y sancionar, de ser el caso, actos de publicidad en el mercado de valores, que generen confusión o error (particularmente en el caso de ofertas públicas de valores mobiliarios y otros actos relacionados con su colocación, distribución o compra). En primer término, porque de la lectura concordada y atenta de la Ley de Normas de Publicidad en Defensa del Consumidor y la LMV se pueden advertir las facultades especiales que le han sido otorgadas a Conasev. En segundo lugar, porque la legislación del mercado de valores tiene una naturaleza especial frente a la de protección al consumidor, sin perjuicio de que, como veremos más adelante, la publicidad sobre ofertas públicas de valores mobiliarios no califica, en estricto, como "publicidad comercial", concepto que es materia de regulación por parte de la Ley de Normas de Publicidad en Defensa del Consumidor.

Queremos aclarar, por otro lado, que nuestro análisis se encuentra limitado a la competencia de Conasev sobre publicidad de ofertas públicas de valores mobiliarios y vía cualquier modalidad de captación (lo que incluye a los fondos mutuos de inversión en valores, por ejemplo). En consecuencia, no nos referiremos a la publicidad de los agentes profesionales que participan en el mercado de valores respecto

\footnotetext{
lineamientos, nos obliga a expresar nuestro punto de vista para generar el debate correspondiente o impulsar al regulador del mercado de valores a publicar sus propias conclusiones, si es que adopta nuestra línea de análisis, en defensa, creemos, de lo que por ley debe ser de su competencia exclusiva para un mejor desarrollo del mercado de valores.
} 
a su calidad de tales o anunciando los servicios que ofrecen (sociedades agentes de bolsa o sociedades administradoras de fondos mutuos de inversión en valores, por ejemplo).

\section{ANÁLISIS LEGISLATIVO}

Este análisis es simple $\mathrm{y}$, hasta cierto punto, categórico, según nos parece. Ciertamente, el artículo 29 de la Ley de Normas de Publicidad en Defensa del Consumidor, como se apreció, señala que sólo la Comisión de Represión de la Competencia Desleal del Indecopi es la facultada a aplicar sanciones en materia de publicidad comercial, estando prohibido para cualquier otro organismo del Estado imponer sanciones en dicha materia.

Si bien la norma legal en cuestión prescribe que a partir de su vigencia el Indecopi es la única entidad estatal competente para los efectos de imponer sanciones en materia de publicidad comercial, debe advertirse que su vigente redacción fue impuesta por el decreto legislativo 807 de 18 de abril de 1996; la LMV, decreto legislativo 861 , en cambio, es de 21 de octubre del mismo año. Por otro lado, el artículo 7 de la LMV dispone que Conasev es la institución del Estado encargada de la supervisión y el control del cumplimiento de dicha ley, la misma que señala que la publicidad que induzca a error o confusión en materia de ofertas públicas se encuentra prohibida.

Podemos concluir, entonces, válidamente, que cuando el decreto legislativo 861 entró en vigencia el 6 de diciembre de 1996, la prescripción del artículo 29 de la Ley de Normas de Publicidad en Defensa del Consumidor vio restringido su ámbito de aplicación, en la medida en que una norma del mismo rango, posterior $\mathrm{y}$, sobre todo, especial, asignó facultades expresas a Conasev para regular, intervenir y, eventualmente, sancionar aquellos actos de publicidad sobre ofertas públicas de valores mobiliarios, que induzcan a error o confusión. Podemos hablar, en todo caso, de una derogación tácita de facultades, pues las prerrogativas de Conasev son específicas y bastante claras.

Por lo tanto, a través de una simple interpretación concordada de las normas legales en mención, puede concluirse que Conasev es competente para hacer cumplir el artículo 11 de la LMV, dado que sus facultades son especiales y posteriores. Es curioso que el Indecopi, en el momento de emitir los lineamientos que más adelante analizaremos, no haya advertido que una norma del mismo rango, especial y posterior, haya restringido el alcance del tantas veces aludido artículo 29 de la Ley de Normas de Publicidad en Defensa del Consumidor.

\section{ANÁLISIS CONCEPTUAL}

Nuestro razonamiento, sin embargo, no debe limitarse a las normas legales referidas; existe un tema conceptual que debe ser expuesto para una mejor comprensión de nuestras conclusiones.

En efecto, la regulación sobre protección al consumidor - al margen de la fecha en que haya entrado en vigencia la norma legal correspondiente- es una legislación de carácter general, mientras que la legislación sobre el mercado de valores es especial debido a la naturaleza de los "productos" que en este mercado se comercializan (valores mobiliarios). Esto no sólo ha generado la necesaria existencia de regulación específica para el mercado de valores 
y de un órgano estatal especializado a efectos de su supervisión eficiente, sino también que la publicidad de las ofertas públicas sobre valores mobiliarios no pueda calificar como "publicidad comercial", concepto que es utilizado en las normas sobre protección al consumidor.

\subsection{Especialidad de la legislación del mercado de valores. Eficiencia en la supervisión}

- El inversor en el mercado de valores puede ser considerado, en sentido lato, como un "consumidor de productos financieros". Así, podría afirmarse que bastaría la legislación sobre protección al consumidor para cautelar sus legítimos intereses, en tanto se trataría de un consumidor más. Como quiera que dicha legislación obliga a los proveedores de bienes y servicios a informar sobre las características y cualidades intrínsecas de los productos que ofrecen para que el consumidor pueda valorarlos de una manera adecuada y así adoptar una decisión racional, los emisores de valores mobiliarios podrían sujetarse a tal regulación y así se atenuaría la evidente asimetría informativa que existe entre el vendedor y el consumidor de cualquier bien o servicio.

No obstante, la especial característica de los valores mobiliarios ${ }^{9}$ origina la existencia de un marco de protección especial para aquellos que decidan adquirirlos o transferirlos. La asimetría informativa en el mercado de valores, al ser más marcada, hace que el Estado emita normas especiales. Contrariamente a lo que ocurre en los demás mercados de bienes y servicios, la información relevante de un emisor de valores mobiliarios - a efectos de calcular el riesgo que su adquisición implica $\mathrm{y}$, consecuentemente, determinar su precio- se encuentra de manera exclusiva en su poder: puede decirse que el emisor "monopoliza" tal información. Efectivamente, nadie mejor que el emisor conoce el estado de sus negocios y la estructura exacta de su patrimonio e ingresos, condiciones que son las que permitirán advertir su verdadera capacidad para cumplir con sus obligaciones. Del mismo modo, la determinación del precio de un valor mobiliario requiere de información de difícil procesamiento, dado que dicho valor representa un derecho sobre los activos de la empresa emisora y/o los flujos de efectivo que pueda generar en el futuro. Sin duda, calcular el precio de un valor mobiliario a partir de la posibilidad de generar tales flujos requiere de información mucho más pormenorizada y especializada que la que comúnmente se requiere para determinar el valor de cualquier otro bien o servicio.

En el mercado de automóviles, por citar un ejemplo, si bien existe asimetría informativa entre vendedor (fabricante o distribuidor) y consumidor, la misma es atenuada de manera natural por la existencia de otros agentes que cuentan con la misma información o con una muy similar. El consumidor puede cerciorarse sin mayor costo a través de otros medios de si el producto ofrecido satisface sus expectativas y si el precio pagado es el adecuado (amistades, familiares, otros expertos, etc.). Y así podríamos mencionar a la gran mayoría de bienes y servicios que son ofrecidos a personas naturales y/o jurídicas como 
destinatarios finales. Las disposiciones sobre protección al consumidor, en nuestra opinión, parten de la premisa de que el consumidor conoce o puede conocer información básica sobre el bien o producto que se le ofrece. Quién no ha adquirido un televisor, prendas de vestir, artículos de tocador, entre otros productos, para poder concluir que en el mercado de bienes y servicios, diferente del de valores, el consumidor conoce de antemano las características básicas de la gran mayoría de los productos que se le ofrecen y puede intuir a priori en algunos casos si lo que le están ofreciendo responde o no a sus intereses. Esto no quiere decir que la regulación sobre protección al consumidor sea innecesaria; por el contrario, su imposición ocasiona mayor eficiencia. Lo que queremos señalar es que en mercados no tan sofisticados como el de valores es más fácil obtener información básica sobre los productos que se ofertan, y las fuentes alternativas para obtener similar información no son tan costosas.

En cambio, en el caso de valores mobiliarios, el "consumidor" sólo puede conocer si el "producto" satisface sus expectativas si es que el emisor revela información adecuada sobre sí mismo (sin perjuicio del análisis de determinados factores externos como las variables macroeconómicas, por ejemplo). $\mathrm{Y}$ es que únicamente el emisor está en capacidad de conocer si puede cumplir o no con sus obligaciones, y el verdadero riesgo que un inversionista asume con la adquisición de su valor; en consecuencia, debe revelar toda la información sobre el estado de sus negocios para que el "consumidor" pueda conocer los riesgos de su inversión y, en tal sentido, asignar un precio adecuado.
No es posible que el inversor adquiera similar información, al menos a bajos costos, si es que el emisor no revela información sobre sí mismo. Es por ello que existe un sistema normativo especial que obliga a proporcionar información diferente de la exigida por la legislación sobre protección al consumidor.

Expuestas así las cosas, es evidente que nos encontramos con supuestos de regulación normativa distintos. Siendo claro, a nuestro entender, que el ámbito de aplicación de la Ley de Normas de Protección al Consumidor no debería alcanzar al "consumidor" de "productos financieros" en el mercado de valores, la Ley de Normas de Publicidad en Defensa del Consumidor tampoco tendría que excederlo, al menos no hasta alcanzar un ámbito con regulación específica previa ${ }^{10}$.

10 Conviene mencionar lo siguiente. Los lineamientos del Indecopi sobre publicidad comercial hacen alusión a una jurisprudencia que establece que "... a diferencia de la legislación sobre protección al consumidor, las normas en materia de publicidad comercial tienen una concepción más amplia de los sujetos beneficiados con la protección concedida por dicho cuerpo legal, incluyendo dentro de los mismos a todo aquel que pueda recibir un mensaje publicitario, independientemente del lugar que ocupe dentro de la cadena de la producción. Así, para el decreto legislativo 691, constituye 'consumidor' no sólo el usuario final de los productos o servicios anunciados, sino también los distribuidores, comerciantes $\mathrm{y}$, en general, todo aquel que se encuentre en la posibilidad de recibir el mensaje del anunciante...". Esto se concluyó en la resolución 004-2000/CCD-Indecopi, emitida en el expediente 072-1999/CCD. Sin embargo, en nuestro concepto, esta mayor cobertura de protección que parecería razonable dado el mayor alcance que tiene la publicidad comercial entre potenciales consumidores, no justifica incluir dentro de las competencias del Indecopi a la publicidad de las ofertas públicas de valores mobiliarios, ya que existe un sistema normativo especial. 
- Por otro lado, la participación de Conasev en la regulación de la publicidad sobre ofertas públicas debe ser preferida para que exista una supervisión más eficiente en el mercado de valores. En este orden de ideas, debe tenerse en cuenta que la publicidad en materia de ofertas públicas es una condición necesaria -aunque no sustancial-para la formulación de éstas, de tal modo de poder cumplir de manera eficiente el objetivo de quien las formula (obtener financiamiento, conseguir liquidez para determinado valor, tomar el control de una empresa, entre otros, dependiendo del caso). Precisamente, las ofertas públicas califican como "públicas" -valga la redundancia-, entre otros aspectos, porque el oferente hace conocer su intención de colocar, comprar o vender valores, según se trate, mediante la utilización de medios masivos de comunicación (aunque debe quedar claro que la utilización de estos medios no es requisito esencial para que una oferta de valores mobiliarios sea considerada pública).

Ciertamente, la oferta de valores mobiliarios también es pública porque va dirigida a captar el ahorro del público, es decir, de una masa indiferenciada, indiscriminada y no predeterminada de ahorradores. El público (o un segmento de éste) debe estar conformado por una pluralidad de personas no identificadas por su relación con el emisor u oferente, las cuales se encuentran desconectadas entre sí y sin injerencia sobre el destino de los fondos (así, sin necesidad de publicar un aviso en los periódicos o de difundirlo a través de la radio, podemos estar frente a una oferta pública de valores mobiliarios si es que se utiliza, por ejemplo, el sistema denominado "de puerta en puer- ta"). Según José Enrique Cachón Blan$\mathrm{co}$, para que una oferta pública de valores negociables pueda ser conceptuada como tal, debe reunir tan sólo las siguientes características:

- en primer lugar, tener por objeto valores negociables.

- en segundo lugar, cumplir una función financiera para el sujeto oferente...

- en tercer lugar, dirigirse a un público indeterminado a priori, es decir, que el público destinatario resulte identificable por determinadas características o cualidades (por el contrario, la posibilidad de determinación o no del nombre de los destinatarios no es esencial), determinándose adentro del citado colectivo los aceptantes de la oferta, para los que la oferta pública constituye un medio de canalización del ahorro. La indeterminación y amplitud del público destinatario de la oferta implica la existencia de un mecanismo de comunicación o publicitario con dicho público: por ello, oferta pública de valores es equivalente a oferta de valores al público.

- en cuarto lugar, estructurarse mediante un procedimiento tal que excluya las negociaciones directas entre las partes y el intercambio individualizado de información y que fije condiciones estandarizadas para los inversores comprendidos dentro del ámbito de la oferta. Por ello se hace precisa la existencia de una normativa que, con la finalidad de tutelar los intereses de los inversores, exija la difusión de una amplia información relativa a la oferta pública en cuestión y a la sociedad emisora de los valores, por cuanto el inversor particular no podría normalmente por sí solo acce- 
der $\mathrm{u}$ obtener del oferente dichas informaciones en forma directa ${ }^{11}$.

Como se puede distinguir, los elementos i) destinatario de la oferta (público indeterminado a priori) y ii) imposibilidad de negociación y trato directo, son los elementos fundamentales para calificar una oferta pública. Por eso, cuando se señala que la publicidad de la oferta pública no debe inducir a error o confusión, debe entenderse que los anuncios o declaraciones dirigidos al público, a través de medios masivos o no de comunicación, no deben generar dichas distorsiones. Lo que ocurre es que hoy en día los medios de comunicación social son los mecanismos más eficientes para poder llegar a esa masa indiscriminada de potenciales suscriptores, adquirentes $o$ aceptantes.

La utilización de tales anuncios debe ser regulada y supervisada, dado el gran uso de éstos. En efecto, la intervención de Conasev no puede limitarse a asegurar el cumplimiento del principio del full disclosure por parte de las empresas para el caso de emisiones primarias, por ejemplo, sin regular y supervisar las actividades propias de la colocación o distribución de valores mobiliarios. No sería muy eficiente -a fin de cumplir con los propósitos de la legislación del mercado de valores- que el órgano regulador se limitara a garantizar la puesta a disposición de la información sin tener control efectivo sobre las actividades concretas relativas al intercambio de dicha información y a la celebración de actos jurídicos con valores mobiliarios, ya que mediante estas actividades pueden vulnerarse muchas prescripciones elementales, como veremos a continuación, aun cuando

11 CACHON BLANCO, José Enrique. Las ofertas públicas de venta de valores negociables. Madrid: Dykinson, S.L., 1997, pp. 57 y 58. se hubiera cumplido con aquellas obligaciones de carácter formal ${ }^{12}$.

Así, la publicidad en materia de ofertas públicas puede llegar a convertirse en un mecanismo de distorsión y violación de los principios de transparencia y correcta formación de precios, aun cuando exista información completa y veraz "registrada" ante el organismo estatal competente. Efectivamente, las actividades de difusión de la oferta pueden sugerir que la revisión de la información "registrada" no es necesaria para la adopción de inversiones racionales; o se puede difundir información adicional (o de manera tal que genere confusión: información contradictoria, por ejemplo) a la del prospecto informativo; entre otras actividades. En tales casos, los precios no reflejarían de manera real la información suministrada por el emisor; los agentes económicos asumirían riesgos sin verse compensados en algunos casos por la rentabilidad adecuada (lo cual es perjudicial para la sociedad en su conjunto, pues ello implicaría asignaciones ineficientes de recursos); la asignación eficiente del ahorro a la inversión productiva,

12 Indudablemente, la obligación de revelar información tiene como propósito que el público al que va dirigida la oferta cuente con los elementos necesarios para adoptar decisiones de inversión racionales. Sin embargo, la sola puesta a disposición no asegura per se que se adopten decisiones eficientes. Son los actos de difusión y colocación de valores los que, en última instancia, van a lograr que se produzca el intercambio de información. Por tanto, el proceso de colocación o distribución (actos de intermediación) también debe encontrarse regulado y supervisado por el organismo especializado, con la finalidad de que la información llegue a los destinatarios de la oferta de la manera más objetiva posible. La publicidad, como sencillamente se puede advertir, juega un rol destacado en este intercambio de información, no sólo porque da a conocer la existencia de la oferta, sino que en muchas oportunidades contiene sus características más importantes. 
finalidad fundamental de la regulación del mercado de valores, no se podría alcanzar en ciertos supuestos, no por haber suministrado información falsa o incompleta, sino porque la publicidad de la oferta habría inducido a error o confusión en los inversionistas. De alli la importancia de que sean materia de regulación normativa y supervisión efectiva por parte del regulador especializado -por tanto, idóneo- los aspectos vinculados a la publicidad de las ofertas públicas de valores mobiliarios y otros actos relacionados con ellas.

La legislación no debe dejar de reconocer este aspecto. Las competencias de Conasev devendrían incompletas si se toma por correcta la interpretación que señala que toda publicidad -sin excepción- es materia de regulación y control exclusivo del Indecopi: tendríamos un regulador de valores casi mutilado. En suma, para qué tener un regulador del mercado de valores especial si algunas de sus competencias "naturales" van a ser delegadas a otros organismos, sea por efecto de la misma legislación o por erróneas o excesivas interpretaciones de ella.

Puede advertirse, a manera de ejemplo, que en España la Comisión Nacional del Mercado de Valores cuenta con facultades expresas en materia de control de la publicidad. Así, conforme al artículo 94 de la Ley del Mercado de Valores española:

El Ministerio de Economía y Hacienda determinará los casos en que la publicidad de las actividades contempladas en esta Ley estará sometida a autorización o a otra modalidad de control administrativo a cargo de la Comisión Nacional del Mercado de Valores, y aprobará, en general, las normas especiales a que la misma habrá de sujetarse.

La Comisión Nacional del Mercado de Valores ejercerá las acciones procedentes con el objeto de conseguir la cesación o rectificación de la publicidad que resulte contraria a las disposiciones a que se refiere el párrafo anterior o que en general deba reputarse ilícita conforme a las normas generales en materia publicitaria, sin perjuicio de las sanciones que resulten aplicables de acuerdo con el capítulo siguiente de esta Ley.

Por otra parte, debe advertirse que en nuestra legislación, en el ámbito reglamentario, existen regulaciones específicas destinadas a controlar la publicidad en materia de ofertas públicas. Así, según el inciso $c$ del artículo 20 del Reglamento de Oferta Pública Primaria -aprobado por resolución 141-97-EF/94.10-, prescripción relativa a la precolocación o preventa de valores, la difusión que se realice sobre los valores mobiliarios, una vez comunicada la intención de realizar la oferta pública, debe ajustarse (entre otros factores) a las disposiciones adicionales que la Gerencia General de Conasev pudiera establecer.

Por su parte, el inciso $d$ del artículo 25 del mismo reglamento señala que una vez inscritos los valores y registrado el prospecto informativo, puede efectuarse la oferta pública propiamente dicha; la difusión que se haga de la invitación deberá ajustarse a las disposiciones adicionales que la Gerencia General de Conasev pudiera establecer. Si bien el reglamento en cuestión no especifica las reglas que deben seguirse y aún no se han emitido normas específicas, consideramos que tales disposiciones tienen por finalidad establecer los parámetros a los que debe sujetarse la publicidad de las ofertas, a efectos de respetar los principios que subyacen a la regulación del mercado de valores y que eventualmente pueden verse trasgredidos por los actos de difusión de la oferta (que, lógicamente, incluyen los avisos de los medios masivos de comunicación).

Del mismo modo, de acuerdo con el artículo 8, numeral 4, del Reglamento de 
Oferta Pública de Adquisición y de Compra de Valores -aprobado por resolución Conasev 630-97-EF/94.10-, la formulación de una Oferta Pública de Adquisición (OPA) debe ser comunicada en el mismo día a Conasev y a la Bolsa de Valores, acompañando, entre otros documentos, un modelo de aviso de la oferta a publicar, que debe contener información mínima acerca de la OPA propuesta. En este caso, incluso, la norma prescribe un control previo, supuesto que no es admitido en la publicidad comercial, donde el control es por naturaleza a posteriori. Esta es una clara muestra de cómo la legislación especial responde eficientemente ante la evidente y real diferencia que existe entre el mercado de valores y los otros mercados de bienes y servicios.

Por otro lado, el Reglamento de Fondos Mutuos de Inversión en Valores y sus Sociedades Administradoras -aprobado por resolución Conasev 026-2000EF/94.10- contiene en su Anexo B normas expresas acerca de la publicidad de un fondo mutuo de inversión en valores. Es clara la intención de la normativa de regular aspectos de la publicidad en el caso de fondos mutuos de inversión en valores mobiliarios, que no podrían ser cubiertos por la normatividad general, pues se tratan, definitivamente, de "productos" especiales y complejos del mercado de valores (aunque se crea que no) que deben sujetarse a una regulación específica, máxime si se tiene en cuenta la relevancia y trascendencia sociales de su utilización hoy en día (muchos pequeños ahorradores utilizan los fondos mutuos como opción de ahorro). Por nuestra parte, opinamos que el tema de la publicidad de los fondos mutuos se está tomando muy a la ligera por las autoridades, al considerar muchas personas que estos productos son similares a los que la banca comercial ofrece (por el nivel de riesgo). Esta distorsión no sólo se ha producido, en nuestro concepto, por la inadecuada y confusa publicidad que las empresas bancarias realizan en sus establecimientos, sino porque actualmente es el Indecopi el que, de hecho, supervisa la misma $^{13}$.

En conclusión, siendo el mercado de valores un mercado especializado y sofisticado, teniendo la publicidad una importancia relevante en las transacciones con valores mobiliarios y existiendo a la fecha normas de carácter reglamentario que buscan regular la publicidad de las ofertas públicas de valores mobiliarios, Conasev es el llamado a contar con competencia exclusiva en materia de publicidad de las ofertas públicas. Caso contrario, se haría aún más dificultoso de lo que ya es hoy

13 En los lineamientos difundidos por el Indecopi se hace expresa mención a la publicidad de los fondos mutuos de inversión en valores como materia de su exclusiva competencia. Incluso, es de nuestro conocimiento que existe un caso, resuelto por el aludido ente, sobre publicidad de los fondos mutuos, que contó con la "opinión" de Conasev para su "mejor" resolución -como si esta comisión fuera una instancia previa o un órgano que debe limitarse a analizar la normativa del mercado de valores para que luego sea aplicada por Indecopi (siempre que éste, incluso, comparta la posición de Conasev, ya que podría tener un criterio distinto)-. Entendemos que, en este caso, Conasev identificó infracciones a las normas del mercado de valores y propuso sanciones. El Indecopi, aplicando su normatividad general, consideró que algunas infracciones aludidas por Conasev no se habían cometido. Ésta es una situación, desde nuestro punto de vista, nada coherente con la especialidad que posee el mercado de valores y que, además, no contribuye en lo absoluto a un mejor desarrollo de este mercado. Por ello es que muchas veces se ha mencionado que no es suficiente contar con "buena" legislación para desarrollar el mercado de valores. Es también necesario tanto un eficiente nivel de enforcement del órgano regulador -el cual debe empezar por reclamar atribuciones que por naturaleza le corresponden-, como la no interferencia de otras entidades gubernamentales que regulan y supervisan mercados diferentes. 
día conseguir desarrollar un mercado de valores peruano líquido, profundo y eficiente.

\section{2 "Publicidad comercial" y publicidad en materia de ofertas públicas sobre valores mobiliarios: diferencias}

Una razón adicional por la que el artículo 29 de la Ley de Normas de Publicidad en Defensa del Consumidor no resulta aplicable a la publicidad de las ofertas públicas en el mercado de valores, es el hecho de que tal publicidad no califica, en estricto, como "publicidad comercial". Ello porque la naturaleza propia del mercado de valores hace que la publicidad en materia de ofertas públicas deba ser entendida como una mera difusión de la existencia de la oferta, sin que la misma consista en una técnica sugestiva orientada a captar, atraer o convencer mayores inversores, finalidad esencial de la publicidad comercial.

Efectivamente, las normas sobre publicidad cuyo cumplimiento es competencia del Indecopi están dirigidas a la denominada "publicidad comercial", que, en nuestro concepto, es distinta a la difusión que se realiza en medios masivos de comunicación sobre las ofertas públicas de valores mobiliarios. En términos generales, a dicha difusión puede llamársele "publicidad", pero sólo si la entendemos a ésta en su acepción más amplia ${ }^{14}$, acepción que reco-

14 Según el Diccionario de la Real Academia Española, publicidad significa (en sus dos acepciones más generales): 1.- calidad o estado de público; 2.- conjunto de medios que se emplean para divulgar o extender la noticia de las cosas o de los hechos. El verbo publicar, por su parte, en sus dos acepciones más generales, significa: 1.- hacer notoria o patente, por televisión, radio, periódicos o por otras medios, una cosa que se quiere hacer llegar a noticia de todos. 2.- hacer patente y manifiesta al público una cosa. ge el artículo 11 de la LMV y que se contrapone a lo que se entiende por "publicidad comercial".

Así, de acuerdo con el documento publicado por Indecopi en el diario oficial El Peruano con fecha 20 de julio de 2001, "Lineamientos sobre Competencia Desleal y Publicidad Comercial", aprobado por resolución 001-2001-LIN-CCD/Indecopi -en adelante "el documento"-, la publicidad comercial es definida como

... una forma de comunicación pública que busca fomentar, directa o indirectamente, la adquisición de bienes o la contratación de servicios, captando o desviando las preferencias de los consumidores (p. 22 del documento).

\section{El mismo documento (p. 22) señala:}

Para que una forma de comunicación constituya "publicidad comercial" deben concurrir dos requisitos:

i) debe tratarse de una comunicación pública, en otras palabras, debe estar dirigida a un público de potenciales consumidores; $y$

ii) dicha comunicación debe tener como propósito o por efecto fomentar en el destinatario del mensaje el consumo de los bienes o la contratación de los servicios anunciados.

Y concluye (p. 22):

La "publicidad comercial" cumple una triple función:

a) función informativa: dar a conocer al público la existencia y las características del bien o servicio anunciado;

b) función persuasiva: convencer al consumidor de que el bien o servicio anunciado satisface sus necesidades y que, por tanto, debería ser elegido entre los demás que se ofrecen en el mercado; y

c) mecanismo de competencia. 
Como se aprecia de lo transcrito, el propósito de la publicidad comercial ${ }^{15}$ es "fomentar en el destinatario del mensaje el consumo de los bienes o la contratación de los servicios anunciados". El anunciante busca colocar sus productos, induciendo al consumidor a adquirirlos, vía la difusión de mensajes persuasivos que no necesariamente corresponden con la realidad; puede recurrir a la fantasía, la exageración, la comparación de productos, etc. Es una técnica utilizada para persuadir al consumidor a adquirir determinado producto: mucho más que un medio de información, la publicidad comercial es un mecanismo adicional -sugestivo, fundamentalmente, y muy eficaz- para lograr la colocación de un producto determinado. Existen, como es conocido, técnicas especializadas, estudios de mercado, profesionales de la materia; en nuestros tiempos, la publicidad comercial es una industria importante y especializada cuyo propósito es ayudar a las empresas a vender los productos $\mathrm{y} / \mathrm{o}$ servicios que ofrecen.

En este orden de ideas, como quiera que la publicidad comercial cumple tres funciones, si un anuncio no tiene como propósito cumplirlas no podría calificarse como tal. Con ser esencial, la función informativa tampoco es siempre la más importante; los anuncios publicitarios pueden, en un inicio (para un nuevo producto, por ejemplo) tener una función informativa relevante; pero una vez conocido el producto entre los consumidores, la publicidad simplemente ayudará a venderlo sostenidamente.

15 Una tercera acepción de la palabra publicidad que brinda el Diccionario de la Real Academia Española es: 3.- divulgación de noticias o anuncios de carácter comercial para atraer a posibles compradores, espectadores, etc.
Ciertamente, la publicidad comercial tiene una importante función persuasiva (según el Diccionario de la Real Academia Española, persuadir significa "inducir, mover, obligar a uno con razones a creer o a hacer una cosa"): busca convencer al destinatario del mensaje de que debe comprar el producto, vía la difusión de mensajes sugestivos, incluso fantasiosos. En principio, la publicidad comercial no persuade al consumidor a buscar información sobre el producto, sino sólo a comprarlo directamente del fabricante o proveedor. El sistema establecido, en nuestro concepto, presume que el consumidor cuenta con información sobre el producto antes de que sea publicitado o la puede conseguir a bajo costo vía otros medios, siendo la publicidad comercial, entonces, sólo un mecanismo que incentiva su compra.

La última función de la publicidad que el documento ("Lineamientos sobre competencia desleal...") menciona es la de mecanismo de competencia. La gran mayoría de productos o servicios son transados en el mercado en condiciones de competencia por el lado de la oferta, es decir, existe más de un fabricante o distribuidor del bien o servicio respectivo. Definitivamente, cada producto puede adquirir características particulares que lo hagan bastante distinguible de otros de su especie, pero dentro de un género similar; es necesario, en consecuencia, utilizar la publicidad comercial para desplazar a la competencia y para que el consumidor no adquiera sus productos.

No es común que se haga publicidad comercial de bienes o servicios que son transados en el mercado en condiciones de monopolio, precisamente porque su fabricante o proveedor no tiene que persuadir a consumir el producto que ofrece, ni eliminar o desplazar a la competencia. Bien podría no realizar publicidad y su 
bien o servicio se consumiría de todas formas (póngase como ejemplo el servicio de telefonía fija, la distribución de electricidad o el servicio de agua potable, al menos en el Perú). Y si bien las empresas monopólicas pueden anunciar en los medios masivos de comunicación, la finalidad de estos anuncios estará dirigida a tener una mejor imagen frente al público usuario o frente al regulador del mercado donde operen (en tanto monopólicas, tendría que existir un órgano estatal que regule el mercado para crear artificialmente condiciones de competencia que eviten abusos a raíz de su posición de dominio), pero de ninguna manera esa finalidad será influir en las decisiones de los consumidores o desplazar a un competidor que no existe.

La publicidad sobre ofertas públicas de valores mobiliarios, en cambio, no encuadra en los conceptos mencionados. No busca fomentar la contratación de bienes o servicios captando o desviando preferencias. Cuando se ofrece la compra o venta de valores por oferta pública, utilizando medios masivos de difusión (una oferta de valores se publicita), lo que se busca esencialmente es informar acerca de la existencia de la oferta: la publicidad sobre ofertas públicas tiene una función netamente informativa.

Antes hicimos alusión a la "difusión" de las ofertas, término que en nuestro concepto se ajusta más al término "publicidad" contenido en el artículo 11 de la LMV. Por ello, no debe entenderse que esta norma prohíbe las campañas de publicidad comercial que induzcan a error o confusión, pues, en términos generales, también puede provocarse confusión o error mediante la divulgación o publicación de cualquier mensaje; no es privativo de la publicidad comercial transmitir mensajes confusos o engañosos (para poner un ejemplo: la difusión de una noticia que no se ajusta a la realidad también puede inducir a error o confusión en el público). El artículo 11 de la LMV no se refiere necesariamente a la publicidad comercial de valores mobiliarios, sino a los medios de difusión que se utilizan para dar a conocer al público la existencia de una oferta, sean o no medios masivos de comunicación.

Así, cuando un emisor invita a la suscripción, compra o venta de valores, debe tan sólo indicar la existencia de la oferta, poniendo énfasis en la revisión del prospecto informativo que servirá para adoptar la decisión de inversión del caso. Dada la especial calidad de los "productos" ofrecidos, el inversionista debe decidir si los adquiere o los vende, no influido por mensajes persuasivos (propagandas fantasiosas o exageradas), sino a través de la información puesta a su disposición mediante la entrega del prospecto informativo.

Una campaña muy creativa e intensa dirigida a la colocación de "productos" como los valores mobiliarios, podría generar confusión entre los inversionistas, desviando su atención del prospecto informativo, supuesto que no es deseado por la legislación del mercado de valores. La fantasía o la exageración propia de la publicidad comercial o el uso de sutiles técnicas persuasivas, del mismo modo, podrían inducir a confusión o error. Es claro que para productos con abundante información en el mercado y de fácil acceso, las técnicas mencionadas pueden ser admitidas dado que un consumidor razonable entenderá que se trata de un mensaje que sólo busca captar su atención. Pero en materia de valores mobiliarios, como la información es "monopolizada" por el emisor, es sofisticada y no existen mecanismos alternos para que el consumidor obtenga información de manera eficiente, el proceso de transmisión de información debe producirse de la manera más clara y objetiva posible. 
Por tanto, cualquier mensaje persuasivo (asegurando un rendimiento, señalando que no existe riesgo en la inversión, garantizando una mejora en la situación económica del inversionista, la seguridad de su dinero, el mejor precio en el mercado para su "producto", por ejemplo) puede generar error o confusión por la clara nota de subjetividad que se encuentra presente en un mensaje de esa naturaleza; de lo que se colige que cuando un emisor, su agente estructurador $\mathrm{y} / \mathrm{o}$ agente colocador hagan de conocimiento público la existencia de una oferta, tal acto debe tener tan sólo naturaleza informativa $y$ no pretender constituirse en un mecanismo adicional en el cual el inversionista base su decisión de invertir.

Con lo anterior no estamos negando la posibilidad de que los emisores, conjuntamente con sus estructuradores o agentes colocadores, realicen publicaciones o presentaciones (road shows) acerca de los valores mobiliarios que emiten, compran o venden, sino que ellas deberían limitarse a transmitir lo que el prospecto informativo señala de una manera resumida y a dar información de la manera más objetiva posible. Esta objetividad, como se vio, se encuentra ausente en la publicidad comercial por el elemento subjetivo de la persuasión y porque sirve fundamentalmente como mecanismo de competencia.

Por otro lado, no cabe utilizar la publicidad comercial en las ofertas de valores mobiliarios, como mecanismo de competencia, porque los emisores son en extremo beterogéneos. Los papeles que emiten reflejan, cada uno de ellos, distinto grado de riesgo, dependiendo del sector económico donde se encuentren ubicados los emisores o de las dimensiones de sus negocios, incluso en empresas del mismo sector. Una empresa bien posicionada del sector minero, por ejemplo, no competirá con otra no tan solvente, pues el riesgo de la primera sería evidentemente menor; cada cual buscará el mercado que esté dispuesto a asumir el riesgo que cada una de ellas representa. Así sean dos empresas mineras muy solventes, una puede producir mayoritariamente oro mientras que la otra puede producir mayoritariamente cobre. No siempre el precio de todos los metales suben o bajan uniformemente. $\mathrm{Si}$ así lo hiciesen, en el extremo, tendrían que lanzar su oferta en el mismo momento. Aun en mercados desarrollados, es un tanto difícil que esta situación ocurra. En todo caso, de ocurrir el último supuesto, la labor del emisor y/o los colocadores debe ser lo más objetiva posible a efectos de no causar distorsiones en la formación de precios o en las preferencias del inversionista.

En este orden de ideas, nos cuesta imaginar un comercial televisivo que muestre a una persona descansando muy placenteramente en una playa paradisíaca, mientras una voz en "off" expresa: "Viva tranquilo y seguro adquiriendo valores $\mathrm{X}$, porque su rendimiento es garantía de ganancia absoluta", luego de lo cual aparece el cónyuge de la persona que representa al inversionista, junto a sus hijos, todos realmente alegres por haber adquirido lujosos productos con el dinero de los intereses, dividendos o ganancias de capital que pudieran haber aprovechado. Ningún emisor puede garantizar tanta felicidad, y así quede claro que se trata de una exageración moderada, el delicado análisis de la información -compleja, por lo demás- que se tiene que realizar para adquirir un valor mobiliario, debe hacer pensar al regulador - legislador dos veces, antes de permitir una campaña de tal naturaleza, máxime cuando dichas campañas se encontrarían dirigidas al pequeño ahorrador, a captar el ahorro de las "viudas y huérfanos" -empleando un eufemismo usualmente esgrimido 
en el mercado de valores para hacer referencia a quienes requieren mayor protección estatal en la toma de decisiones (a través, claro está, de la puesta a disposición de toda la información relevante sobre el emisor, la oferta y el valor).

Por lo tanto, cuando el artículo 11 de la LMV declara que

la publicidad relativa a la emisión, colocación o intermediación de valores y cualquier otra actividad que se realice en el mercado de valores no debe inducir a confusión o error,

quiere decir que los medios de difusión que se utilicen para revelar la existencia de la oferta pública no deben inducir a error o confusión, debiendo ser, en tal sentido, claros y objetivos. No debe entenderse que se refiere, necesariamente, a la publicidad comercial.

Si se concluye que la publicidad a la que se refiere el artículo 11 de la LMV no es la publicidad comercial regulada por el Indecopi según los términos de sus Lineamientos sobre Competencia Desleal y Publicidad Comercial, Conasev es el único encargado de regular y supervisar todos aquellos anuncios, campañas o medios de difusión que los emisores y/o colocadores realizan en ofertas públicas de valores mobiliarios. Siendo un órgano que conoce el mercado de valores y su regulación mejor que cualquier otro organismo estatal regulador o mera agencia de competencia (Indecopi), aplicará y reglamentará la norma citada de una manera mucho más eficiente.

\section{COMENTARIOS FINALES}

La publicidad de las ofertas públicas de valores mobiliarios es una materia que, desde nuestra perspectiva, merece cuidado en cuanto a su regulación y supervisión; es un aspecto que, por lo demás, es propio de la regulación del mercado de valores. $\mathrm{Si}$ bien el Indecopi ha desplegado una importantísima labor para regular y supervisar de manera eficiente la publicidad comercial -habiendo tratado de abarcar muchos supuestos en sus lineamientos institucionales, para lograr una mejor aplicación de la normativa-, creemos que Conasev es el único llamado a supervisar todo lo concerniente al mercado de valores, dada su especialidad en la materia.

Nuestro análisis es modesto. Esperamos haber alcanzado algunas luces a los órganos estatales comprometidos -Conasev e Indecopi- para que en el futuro -a través de un trabajo coordinado y más profundo sobre el tema- no se presenten eventuales conflictos de competencia entre ellos, ya que tales contiendas, a la larga, redundan en perjuicio de los inversores en el mercado de valores. Estos inversores -grandes o pequeños- son necesarios para reforzar esta vía alternativa de financiamiento empresarial que hasta ahora no termina de encontrar una senda adecuada que lo haga verdaderamente accesible a la mayor cantidad de empresas nacionales que requieren financiamiento barato. Una clara delimitación de competencias en la publicidad de las ofertas públicas es una contribución que, aunque pequeña, brinda seguridad a los agentes económicos para su mayor y más frecuente utilización. 